\title{
Correction to: Kasai-Like Portoenterostomy for Multiple Biliary Duct Reconstruction After Extended Liver Resection of Perihilar Cholangiocarcinoma
}

\author{
Antonio Mimmo, $\mathrm{MD}^{1,2}$, Stylianos Tzedakis, $\mathrm{MD}^{1,3}$, Pierre Guéroult, $\mathrm{MD}^{4}$, Dihia Belabbas, $\mathrm{MD}^{5}$, \\ Heithem Jeddou, $\mathrm{MD}^{1}$, and Karim Boudjema, MD, $\mathbf{P h D}^{1}$ \\ ${ }^{1}$ Department of Hepatobiliary and Digestive Surgery, Pontchaillou University Hospital, Rennes, France; ${ }^{2}$ Department of \\ Digestive Surgery, Hospital of Le Mans, Le Mans, France; ${ }^{3}$ Department of Digestive, Hepatobiliary, and Endocrine \\ Surgery, Cochin University Hospital AP-HP, Paris, France; ${ }^{4}$ Department of Visceral Surgery, University Hospital of \\ Angers, Angers, France; ${ }^{5}$ Department of Radiology, Pontchaillou University Hospital, Rennes, France
}

\section{Correction to: Ann Surg Oncol}

https://doi.org/10.1245/s10434-020-09551-x

In the original online version of this article, all of the authors' given and family names were transposed. The original article has been corrected.
Publisher's Note Springer Nature remains neutral with regard to jurisdictional claims in published maps and institutional affiliations.

The original article can be found online at https://doi.org/10.1245/ s10434-020-09551-x.

(C) Society of Surgical Oncology 2021

Published Online: 16 July 2021

K. Boudjema, MD, $\mathrm{PhD}$

e-mail: karim.boudjema@chu-rennes.fr 